\title{
The relationship between sleep duration and obesity risk among school students: a cross-sectional study in Zhejiang, China
}

\author{
Hao Wang ${ }^{1}$, Ruying $\mathrm{Hu}^{1}$, Huaidong Du ${ }^{2,3}$, Bragg Fiona ${ }^{2}$, Jieming Zhong ${ }^{1}$ and Min $\mathrm{Yu}^{1^{*}}$
}

\begin{abstract}
Background: Obesity has been identified as a major risk factor for a large number of chronic diseases. Understanding factors related to adolescent obesity is critical for prevention of chronic diseases. The associations between sleep duration and obesity among adolescents in the existing literature are controversial. Our study was designed to determine the prevalence of short sleep duration, and assess the association of sleep duration and obesity, among middle and high school students in Zhejiang, China.
\end{abstract}

Methods: 18,403 Students in 442 schools were recruited and surveyed using an anonymous, self-administered questionnaires. Weighted multivariable logistic regression models were used for data analyses.

Results: The mean (SD) age of the students was 15.9 (1.8) years. $49.7 \%$ of students were girls. The mean (SD) height and weight were $166.2(8.5) \mathrm{cm}$ and $54.6(11.1) \mathrm{kg}$, respectively. The overall prevalence of obesity and overweight were $3.4 \%$ (95\% Cl: 3.0-3.8) and 7.8\% (95\% Cl: 7.4-8.3), respectively. The overall prevalence of short sleep duration among students was 66.0\% (95\% Cl: 63.8-68.1), higher among girls than boys (69.8\% vs. 62.1\%) $(P<0.0001)$. The figures for middle school, academic high school, and vocational high school were 59.0, 82.4 and 59.7\%, respectively $(P<0.0001)$. As compared with girls who sleep $8 \mathrm{~h}$ per day (reference), the odds ratios $(95 \% \mathrm{Cl})$ of obesity for girls who sleep $<7 \mathrm{~h}, 7 \mathrm{~h}, 9 \mathrm{~h}$ and $\geq 10 \mathrm{~h}$ were 1.97 (1.15-3.38), 1.90 (1.18-3.04), $1.38(0.86-2.20)$ and $2.12(1.22-3.67)$ respectively, after adjustment for socio-demographic status, lifestyle factors, and mental health. The corresponding figures among boys were 1.45 (0.97-2.16), $1.13(0.81-1.57), 1.25$ (0.89-1.74), and 1.12 (0.81-1.54), respectively.

Conclusions: Insufficient sleep is prevalent among students in Zhejiang China. A U-shaped relationship was found between sleep duration and obesity risk among girls, with the lowest risk among those who slept for 8 h, but not among boys. Adequate sleep duration may be an important component of obesity prevention initiatives among adolescents.

Keywords: Sleep duration, Overweight, Obesity, Adolescents, Factors

\section{Background}

Worldwide, the prevalence of overweight and obesity have steadily increased over the last several decades, with the number of obese individuals estimated to reach 711.4 million in 2015, of which 107.7 million were children [1]. Globally, high BMI contributed to 4 million deaths in 2015 , equivalent to $7.1 \%$ of all-cause deaths,

\footnotetext{
* Correspondence: myu@cdc.zj.cn

${ }^{1}$ Department of NCDs Control and Prevention, Zhejiang Provincial Center for Diseases Control and Prevention, \#3399 Binsheng road, Binjiang District, Hangzhou, Zhejiang Province, China

Full list of author information is available at the end of the article
}

and 120 million disability-adjusted life years (DALYs), accounting for $4.9 \%$ of DALYs from any cause among adults [1]. In many countries, obesity rates among children are rising faster than among adults, and this is particularly true in China, which has the highest number of obese children [2].

In China, the prevalence of overweight and obesity among 7-18-year students increased from 1.1 to $9.6 \%$ and from 0.1 to $4.9 \%$, respectively, between 1985 and 2010 , and in 2010 the prevalence of obesity varied from 0.4 to $21.7 \%$ across different provinces in China [3]. 
Zhejiang Province, situated in the east of China, has a population of 56 million. During the past decade, with increasing urbanization and changes in lifestyle, the prevalence of overweight and obesity among adolescents has increased dramatically, reaching 10.6 and 5.3\%, respectively in 2010 [4], higher than the Chinese national average.

Overweight and obesity are well-documented risk factors for a large number of chronic diseases, including diabetes, cancers, strokes, and coronary heart disease [5-7]. Hence, understanding factors related to adolescent obesity is critical for addressing this urgent public health concern. A wide range of factors, including low physical activity, prolonged sedentary time, and unhealthy dietary behaviours, have been found to be adversely associated with adolescent obesity [8-10], and there is a growing literature documenting the relationship of sleep and obesity. However, most studies examining the association of sleep with adiposity among adolescents are from western countries [11, 12], where the patterns of adolescent sleep and obesity may be different from China [13, 14]. Furthermore, the associations between sleep duration and obesity among adolescents in the existing literature remain controversial. While some studies report null associations between sleep duration and obesity $[11,15,16]$, others have found U-shaped $[12,17]$ or negative linear [18] relationships between sleep duration and obesity. A study of 66,817 10-18-year adolescents from China found a U-shaped association of sleep duration and obesity [19], and the current study was designed with the aim of examining the prevalence of short sleep duration and assessing the relationship of sleep duration with obesity among students in Zhejiang Province, China.

\section{Methods}

\section{Sample and procedure}

Details of study design, sample, and participants have been reported previously [20]. Briefly, during April and May 2017, a total of 24,157 students from grades 7-12 in 442 different schools in 30 counties in Zhejiang were invited to participate, with 23,554 students participating in the survey (response rate: 97.5\%). Written informed consent was obtained from all participants and their guardians before the survey. After exclusion of subjects with missing key variables (including sex, height, weight and sleep duration), 18,403 eligible subjects were included in the final analyses (Fig. 1), of whom, 9259 (49.7\%) were girls and the mean $( \pm$ SD) age was $15.9 \pm 1.8$ years. $8834(47.7 \%)$ participants were middle school students, 5597 (29.0\%) were academic high school students and 3972 (23.3\%) came from vocational high school. The survey questionnaire was based on the Youth Risk Behaviour Survey, developed by the Centers for Disease Control and Prevention (CDCs) [21], and the

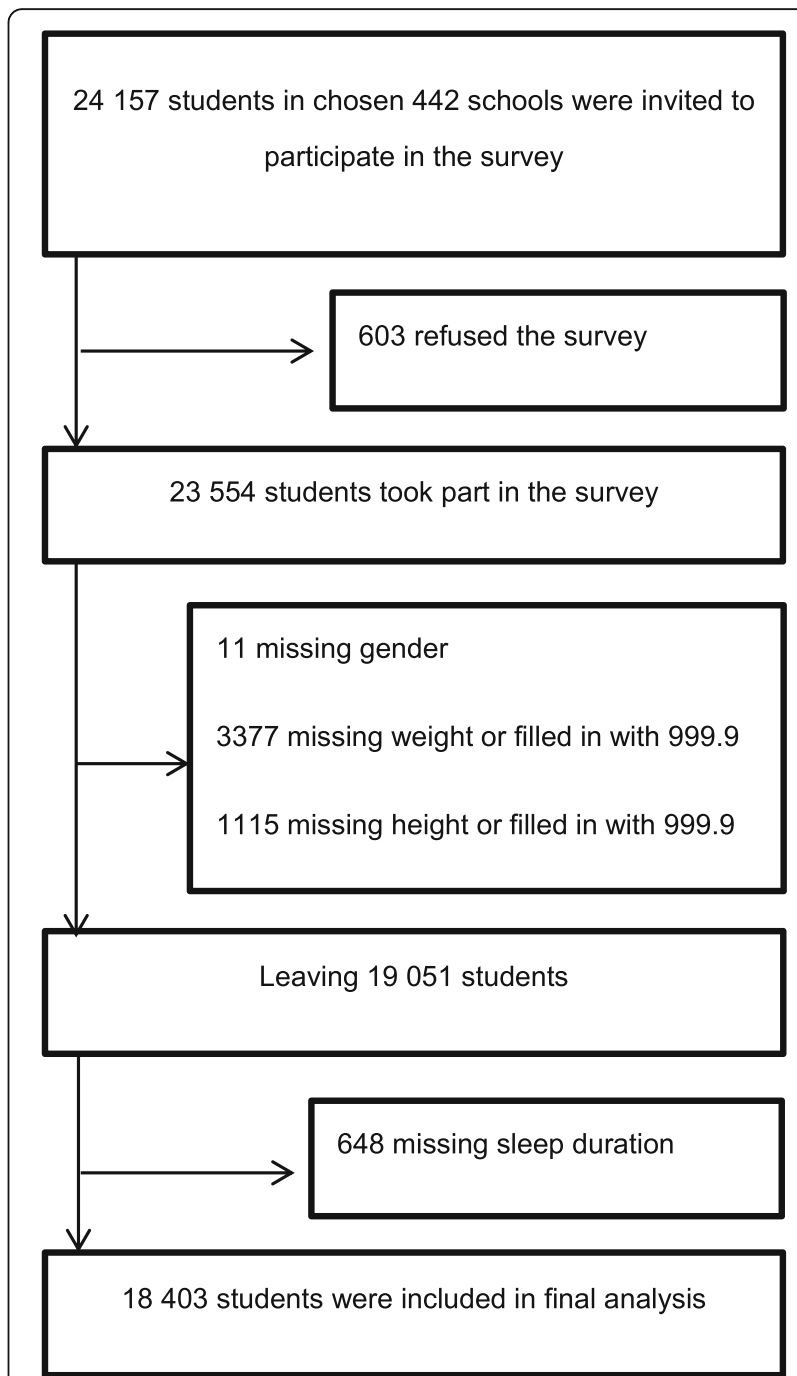

Fig. 1 Flowchart of participants included in final analysis

international Global School-based Student Health Survey (GSHS), supported by the World Health Organization [22]. The questionnaire covered demographic characteristics (birth year and month, parental education), tobacco use, alcohol use, dietary consumption (breakfast, fruit, vegetables, milk, and carbonated beverages), physical activity, screen-time and mental health (loneliness). The self-administrated questionnaire was completed anonymously by students and put directly into sealed boxes after completion. In order to improve the response rate, every recruited student was given a pencil box as a gift. The study design and procedure was approved by the ethics committee of Zhejiang Provincial CDC.

\section{Measures}

Outcome variables

Height was assessed by the question "How tall are you without your shoe on? प्र०. $\mathrm{cm}$ (write your height in 
the blank boxes. If you do not know or refuse, please fill in the blank boxes with 999.9" Weight was assessed by the question "How much do you weigh without your shoes on? प्व०. $\mathrm{kg}$ (write your weight in the blank boxes. If you do not know or refuse, please fill in the blank boxes with 999.9" Body mass index (BMI) was calculated as the ratio of self-reported weight $(\mathrm{kg})$ to the square of self-reported height $(\mathrm{m})$. Standard cut-offs for adolescent overweight and obesity (Table 1), established by Chinese Working Group on Obesity for Children (WGOC) [23], were used in the analyses.

\section{Exposure variable}

Sleep duration was assessed through the question: "During the past 30 days, on average, how long did you sleep every day (including daytime rest)? $\square$ (Hours $\square$ ( Minutes" Sleep duration (hours) was calculated as: hours + (minutes/60). Short sleep duration was defined as sleep duration $<9$ h per day for children aged 6-12 years or $<$ $8 \mathrm{~h}$ per day for teens aged $\geq 13$ years, as recommended by American Academy of Sleep Medicine (AASM) [24].

\section{Other covariates}

Some covariate question and response options (including parental education, cigarette use, alcohol use, physical activity, screen-time, and loneliness) have been reported previously [20]. Breakfast was assessed by the question: "During the past 7 days, on how many days did you eat breakfast?" Answer options included "None", " 1 day", " 2 days", " 3 days", " 4 days", " 5 days", "6 days", and "7 days". Answers were further categorized into two groups: "Daily" and "Nondaily". Fruit intake was assessed by the question: "During the past 30 days, how many times per day did you usually eat fruit, such as apples,

Table 1 Standard cut-offs for overweight and obesity in Chinese children and adolescents

\begin{tabular}{llllll}
\hline Age(years) & \multicolumn{2}{l}{ Overweight } & & \multicolumn{2}{l}{ Obesity } \\
\cline { 2 - 3 } & Boys & Girls & & Boys & Girls \\
\hline $7-$ & 17.4 & 17.2 & 19.2 & 18.9 \\
$8-$ & 18.1 & 18.1 & 20.3 & 19.9 \\
$9-$ & 18.9 & 19.0 & 21.4 & 21.0 \\
$10-$ & 19.6 & 20.0 & 22.5 & 22.1 \\
$11-$ & 20.3 & 21.1 & 23.6 & 23.3 \\
$12-$ & 21.0 & 21.9 & 24.7 & 24.5 \\
$13-$ & 21.9 & 22.6 & 25.7 & 25.6 \\
$14-$ & 22.6 & 23.0 & 26.4 & 26.3 \\
$15-$ & 23.1 & 23.4 & 26.9 & 26.9 \\
$16-$ & 23.5 & 23.7 & 27.4 & 27.4 \\
$17-$ & 23.8 & 23.8 & 27.8 & 27.7 \\
$18-$ & 24.0 & 24.0 & 28.0 & 28.0 \\
\hline
\end{tabular}

oranges, mangoes, or papayas?" Response options included "None", "< 1 time", "1 time", "2 times", "3 times", " 4 times", and " $\geq 5$ times". Answers were further categorized into two groups: "Daily" and "Nondaily". Vegetable intake was assessed by the question: "During the past 30 days, how many times per day did you usually eat vegetables, such as cauliflower, cabbage?" Response options for vegetable intake were identical to those for fruit. Answers were further categorized into two groups: " $\geq 2$ times/day" and " $<2$ times/day". Milk intake was assessed by the question: "During the past 30 days, on how many days per week did you drink milk?" Response options included "None", "< 1 day", "1-2 days", "3-4 days" and "57 days". Options were further divided into two groups: " $<3$ days/week" and " $\geq 3$ days/week". Carbonated beverages were assessed by the question: "During the past 30 days, how many times per day did you usually drink carbonated soft drinks, such as Coca-Cola, Pepsi, or Sprite? (Do not include diet soft drinks.)". Response options included "None", "1-3 times/week", "4-6 times/week", "1 time/d", "2 times/d", "3 times/d", and " $\geq 4$ times/d". Options were further divided into two groups: " $<4$ times/ week" and " $\geq 4$ times/week".

\section{Statistical analysis}

All analyses were performed using SAS software V.9.3. A weighting factor was applied to each student record to adjust for non-response and for the varying probabilities of selection. The weight used for estimation in this survey is given by: $\mathrm{W}=\mathrm{W} 1 \times \mathrm{W} 2 \times \mathrm{f} 1 \times \mathrm{f} 2$. W $1=$ the inverse of the probability of selecting the county. $\mathrm{W} 2=$ the inverse of the probability of selecting the classroom within the county. $\mathrm{f} 1=\mathrm{a}$ student-level nonresponse adjustment factor calculated by class. $\mathrm{f} 2=$ a post-stratification adjustment factor calculated by grade [25]. Continuous variables were given as mean \pm standard deviation. The prevalence of short sleep duration and overweight/obesity were given as percentage and 95\% confidence intervals $(\mathrm{CI})$. Weighted prevalence and weighted mean were calculated using the PROC SURVEYFREQ, and PROC SURVEYMEAN procedure, respectively. Comparison of weighted prevalence was performed using Rao-Scott $x^{2}$, and comparison of weighted mean was performed using design based linear regression.

To examine the associations of sleep duration and obesity, weighted multivariable logistic regression analyses were performed using the PROC SURVEYLOGISTC procedure. In multivariable logistic regression, sleep duration (continuous) was transformed into a categorical variable comprising five groups: " $<7 \mathrm{~h}$ ", "7 h", " 8 h", "9 h", and " $\geq 10$ h". Students who slept 8 h per day were selected as reference group. Three logistic regression models were fitted to assess adjusted odds ratios (ORs) and their 95\% CI. In model 1, ORs were adjusted 
for age group ( $\leq 13 \mathrm{y}, 14-15 \mathrm{y}$, and $\geq 16 \mathrm{y}$ ), sex (boys and girls), area (urban and rural), types of school (middle school, academic high school, and vocational high school), paternal and maternal education level (high school or below, college or above, and unknown). In model 2, ORs were additionally adjusted for cigarette use (current smoker and non-smoker), alcohol use (current drinker and non-drinker), breakfast consumption (daily and nondaily), fruit consumption (daily and nondaily), vegetable consumption $(\geq 2$ times/day and $<2$ times/day), milk consumption ( $\geq 3$ days/week and $<$ 3 days/week), carbonated drinks consumption ( $\geq 4$ times/ week and $<4$ times/week), physical activity (daily and nondaily), and screen-time $(\geq 2 \mathrm{~h} /$ day and $<2 \mathrm{~h} /$ day). In model 3, ORs were additionally adjusted for loneliness (never/occasionally, sometimes and often/always). All statistical tests were two tailed, and $P$-values $<0.05$ were considered statistically significant.

\section{Results}

\section{Descriptive statistics}

The percentage of students whose fathers and mothers were educated to college level or above were 12.2 and $10.7 \%$ (Table 2), respectively. Compared to students with non-short sleep duration, students with short sleep duration had lower physical activity $(19.4 \%$ vs.15.1\%) $(P<$ $0.0001)$, shorter screen-time $(24.2 \%$ vs.16.6\% $) \quad(P<$ $0.0001)$, less frequent consumption of breakfast $(74.0 \%$ vs.69.4\% $)(P<0.0001)$ and fruits $(74.7 \%$ vs. $69.8 \%)(P<$ $0.0001)$, and more frequent feelings of loneliness $(7.4 \%$ vs. $13.2 \%)(P<0.0001)$. Mean student height and weight were $166.2 \pm 8.5 \mathrm{~cm}$ and $54.6 \pm 11.1 \mathrm{~kg}$, respectively. Mean sleep duration was $8.3 \pm 1.6 \mathrm{~h}$ per day. Comparison of included and excluded participants showed no statistically significant differences for the majority of variables examined (Additional file 1: Table S1), but compared to included students, those excluded from the study were more likely to be younger, to be boys, to attend middle school, and to use electronic screen devices, and were less likely to have well-educated parents and to drink alcohol.

\section{Prevalence of obesity and overweight}

The overall prevalence of obesity and overweight were 3.4\% (95\% CI: $3.0-3.8$ ) and 7.8\% (95\% CI: 7.4-8.3), respectively (Table 3 ). The prevalence of obesity among boys was higher than among girls $(4.3 \%$ vs. $2.4 \%)(P<0.0001)$. The corresponding figures for overweight were 10.4 and $5.3 \%$, respectively $(P<0.0001)$. The prevalence of overweight in urban areas was higher than in rural areas $(9.3 \%$ vs. 7.1\%). The prevalence of obesity among middle school, academic high school, and vocational high school students were $4.1,2.2$, and $3.6 \%$, respectively, with corresponding figures for overweight of 7.4, 8.2, and 8.3\%, respectively.

\section{Prevalence of short sleep duration}

The overall prevalence of short sleep duration was $66.0 \%$ (95\% CI: 63.8-68.1), significantly higher among girls than boys $(69.8 \%$ vs. $62.1 \%)(P<0.0001)$, and marginally higher in urban, than rural, areas $(69.5 \%$ vs. $64.2 \%)(P=$ 0.05) (Table 4). The prevalence of short sleep duration among middle school, academic high school, and vocational high school students were 59.0, 82.4 and 59.7\%, respectively $(P<.0001)$. The prevalence of short sleep duration increased with the increasing age $(P<.0001)$.

\section{Associations of sleep duration and obesity}

After adjustment for socio-demographic status (Table 5), compared to girls who slept $8 \mathrm{~h}$ per day, those who slept $<7 \mathrm{~h}, 7 \mathrm{~h}, 9 \mathrm{~h}$, and $\geq 10 \mathrm{~h}$ per day had $86 \%(\mathrm{OR}=1.86$, 95\% CI: $1.08-3.22), 82 \%$ (OR $=1.82,95 \%$ CI: $1.14-2.92$ ), $40 \%(\mathrm{OR}=1.40,95 \% \mathrm{CI}: 0.87-2.24)$, and $109 \%(\mathrm{OR}$ $=2.09,95 \%$ CI: $1.23-3.58)$, respectively higher risk for obesity in model 1 . After additional adjustment for lifestyle factors, girls who slept $<7 \mathrm{~h}, 7 \mathrm{~h}, 9 \mathrm{~h}$, and $\geq 10 \mathrm{~h}$ per day had 96\% (OR $=1.96,95 \%$ CI: $1.14-3.35), 89 \%$ $(\mathrm{OR}=1.89,95 \% \mathrm{CI}: 1.18-3.03), 38 \%(\mathrm{OR}=1.38,95 \% \mathrm{CI}:$ $0.87-2.19$ ), and $113 \%(\mathrm{OR}=2.13,95 \% \mathrm{CI}: 1.23-3.69)$, respectively greater odds for obesity risk compared with the reference group. After further adjustment for loneliness, the corresponding odds ratios $(95 \% \mathrm{CI})$ were 1.97 (1.15-3.38), 1.90 (1.18-3.04), 1.38 (0.86-2.20), and 2.12 (1.22-3.67), respectively. A U-shaped relationship was observed between sleep duration and obesity among adolescent girls. However, no statistically significant difference was found among adolescent boys. The corresponding odds ratios $(95 \% \mathrm{CI})$ for boys were 1.45 (0.972.16), 1.13 (0.81-1.57), $1.25(0.89-1.74)$ and $1.12(0.81-$ $1.54)$, respectively.

\section{Discussion}

This provincially representative survey shows that two-thirds of students experienced insufficient sleep duration. The association between sleep duration and obesity differed by sex; after controlling for socio-demographic status, lifestyle factors, and mental health, a U-shaped relationship was found between sleep duration and obesity among girls, but not among boys.

\section{Overweight/obesity}

Our study found that the prevalence of overweight/obesity derived from self-reported height and weight was $11.2 \%$, lower than in another study of 33,256 7-18-year students conducted in Zhejiang in 2010, which showed a prevalence, derived from objectively-measured data, of $15.9 \%$ [4]. Previous studies have documented that self-reported weight and height might underestimate BMI [26-28]. A study of 24,221 students from 8th and 11th grade in the United States compared the difference 
Table $\mathbf{2}$ Characteristics of adolescents from Zhejiang by sleep duration

\begin{tabular}{|c|c|c|c|c|}
\hline Characteristics & $\begin{array}{l}\text { Total } \\
(N=18,403)\end{array}$ & $\begin{array}{l}\text { Non-short } \\
\text { sleep duration } \\
(N=6184)\end{array}$ & $\begin{array}{l}\text { Short } \\
\text { sleep duration } \\
(N=12,219)\end{array}$ & $P$ value \\
\hline Age (years) & $15.9 \pm 1.8$ & $15.8 \pm 1.8$ & $15.9 \pm 1.8$ & 0.33 \\
\hline Girls (\%) & $9259(49.7)$ & $2774(44.1)$ & $6485(52.7)$ & $<.0001$ \\
\hline Urban (\%) & $7314(33.1)$ & 2133 (29.6) & $5181(34.9)$ & 0.05 \\
\hline Types of school (\%) & & & & $<.0001$ \\
\hline Middle school & $8834(47.7)$ & $3651(57.4)$ & $5183(42.6)$ & \\
\hline Academic high school & $5597(29.0)$ & $922(15.0)$ & $4675(36.3)$ & \\
\hline Vocational high school & $3972(23.3)$ & $1611(27.6)$ & $2361(21.1)$ & \\
\hline Paternal education level (\%) & & & & $<.0001$ \\
\hline High school or below & $10,525(81.5)$ & $5046(82.3)$ & $9636(81.0)$ & \\
\hline College or above & $6787(12.2)$ & $684(9.7)$ & $1946(13.6)$ & \\
\hline Unknown & $1091(6.3)$ & $454(8.0)$ & $637(5.4)$ & \\
\hline Maternal education level (\%) & & & & $<.0001$ \\
\hline High school or below & $11,352(82.7)$ & $5054(82.4)$ & $9875(82.9)$ & \\
\hline College or above & $5880(10.7)$ & $619(9.0)$ & $1684(11.6)$ & \\
\hline Unknown & $1171(6.6)$ & $511(8.6)$ & $660(5.5)$ & \\
\hline Physically active daily (\%) & 3090 (16.6) & $1230(19.4)$ & $1860(15.1)$ & $<.0001$ \\
\hline Screen duration $\geq 2$ h per day (\%) & $3462(19.2)$ & $1521(24.2)$ & $1941(16.6)$ & $<.0001$ \\
\hline Consuming breakfast daily (\%) & $13,036(70.9)$ & $4587(74.0)$ & $8449(69.4)$ & $<.0001$ \\
\hline Consuming fruits daily (\%) & $13,170(71.5)$ & $4648(74.7)$ & $8522(69.8)$ & $<.0001$ \\
\hline Consuming vegetables $\geq 2$ times daily (\%) & $13,746(74.7)$ & 4559 (73.6) & $9187(75.3)$ & 0.08 \\
\hline Consuming milk $\geq 3$ days weekly (\%) & $12,211(66.9)$ & $4164(67.9)$ & $8047(66.3)$ & 0.07 \\
\hline Consuming carbonated drinks $\geq 4$ times weekly (\%) & $2389(12.7)$ & 779 (12.2) & $1610(12.9)$ & 0.35 \\
\hline Current cigarette smoking (\%) & $992(5.5)$ & $371(5.9)$ & $621(5.3)$ & 0.29 \\
\hline Current alcohol drinking (\%) & $4311(23.6)$ & $1400(23.1)$ & $2911(23.8)$ & 0.57 \\
\hline Often/always feel lonely (\%) & $2055(11.2)$ & $447(7.4)$ & $1608(13.2)$ & $<.0001$ \\
\hline Height (cm) & $166.2 \pm 8.5$ & $165.6 \pm 8.8$ & $166.5 \pm 8.3$ & $<.0001$ \\
\hline Weight (kg) & $54.6 \pm 11.1$ & $53.7 \pm 11.5$ & $55.0 \pm 10.8$ & $<.0001$ \\
\hline BMI $\left(\mathrm{kg} / \mathrm{m}^{2}\right)$ & $19.7 \pm 3.3$ & $19.5 \pm 3.5$ & $19.8 \pm 3.1$ & $<.0001$ \\
\hline Sleep duration (hours) & $8.3 \pm 1.6$ & $9.7 \pm 1.0$ & $7.6 \pm 0.8$ & $<.0001$ \\
\hline
\end{tabular}

Mean and number in brackets were weighted

$B M I$ body mass index

between self-reported and objectively-measured height and weight, and found students overestimated their height by $0.68-2.02 \mathrm{~cm}$, and underestimated their weight by $0.4-$ $0.98 \mathrm{~kg}$ [29]. However, when direct measurement of height and weight is not practical, self-reported measurements are suggested to provide a reliable proxy measure among adolescents [29]. In addition, previous studies showed that self-reported height and weight information collected from girls tends to result in greater underestimation of BMI than self-reported height and weight information collected from boys [30, 31], which may explain why the prevalence of overweight and obesity among girls was lower than among boys in our study (overweight: $5.3 \%$ vs. $10.4 \%$; obesity: $2.4 \%$ vs. $4.3 \%$ ).

\section{Short sleep duration}

Globally, increased prevalence of insufficient sleep seems to parallel increased prevalence of overweight and obesity [32]. Our study showed that, although lower than that reported in the United States in 2015 (72.7\%) [33], the overall prevalence of short sleep duration among middle and high school students was $66.0 \%$ in Zhejiang, suggesting two-thirds of students were facing consequences of sleep deficiency. One possible reason for this 
Table 3 Comparison of weighted prevalence of overweight and obesity between different groups

\begin{tabular}{|c|c|c|c|c|c|c|c|c|c|}
\hline \multirow[t]{2}{*}{ Characteristics } & \multicolumn{3}{|c|}{ Overweight/obesity } & \multicolumn{3}{|l|}{ Overweight } & \multicolumn{3}{|l|}{ Obesity } \\
\hline & Prevalence (\%) ${ }^{a}$ & $x^{2 b}$ & $P$ value & Prevalence (\%) ${ }^{a}$ & $x^{2 b}$ & $P$ value & Prevalence (\%) & $x^{2 b}$ & $P$ value \\
\hline Sex & & 189.6 & $<.0001$ & & 104.3 & $<.0001$ & & 41.1 & $<.0001$ \\
\hline Boys & $14.7(13.7-15.7)$ & & & $10.4(9.7-11.1)$ & & & $4.3(3.8-4.9)$ & & \\
\hline Girls & $7.7(7.1-8.3)$ & & & $5.3(4.6-5.9)$ & & & $2.4(2.1-2.8)$ & & \\
\hline Area & & 11.0 & 0.0009 & & 25.6 & $<.0001$ & & 0.0001 & 0.99 \\
\hline Urban & $12.7(11.6-13.9)$ & & & $9.3(8.5-10.1)$ & & & $3.4(2.7-4.1)$ & & \\
\hline Rural & $10.5(9.7-11.3)$ & & & $7.1(6.6-7.6)$ & & & $3.4(2.9-3.9)$ & & \\
\hline Types of school & & 3.2 & 0.2 & & 3.2 & 0.2 & & 25.2 & $<.0001$ \\
\hline Middle school & $11.4(10.5-12.3)$ & & & $7.4(6.8-8.0)$ & & & $4.1(3.5-4.7)$ & & \\
\hline Academic high school & $10.4(9.2-11.5)$ & & & $8.2(7.3-9.1)$ & & & $2.2(1.7-2.6)$ & & \\
\hline Vocational high school & $12.0(10.4-13.5)$ & & & $8.3(7.2-9.5)$ & & & $3.6(2.9-4.3)$ & & \\
\hline
\end{tabular}

${ }^{\mathrm{a}}$ Based on the weighted data. ${ }^{\mathrm{b}}$ Rao-Scott $\mathrm{x}^{2}$

high prevalence is competition pressure from entrance exams, in particular the college entrance exam which is usually viewed as the most important and highly competitive exam in China. This is supported by our observation that compared with students from middle school $(59.0 \%)$ and vocational high school (59.7\%), students from academic high school had the highest prevalence of short sleep duration (82.4\%).

Relationship of obesity and short and long sleep duration More recently, a meta-analysis of prospective studies including 26,652 adolescents aged 12-18 years from 3 different studies in the US, found that short sleep duration was a risk factor or marker ( $\mathrm{RR}=1.3,95 \% \mathrm{CI}$ : $1.11-1.53)$ for the development of obesity among adolescents [34], consistent with our findings that sleep deficiency was

Table 4 Comparison of weighted prevalence of short sleep duration by different characteristics

\begin{tabular}{|c|c|c|c|}
\hline Characteristics & Prevalence $(\%)^{a}$ & $x^{2}$ & $P$ value \\
\hline Age (y) & & $885.8^{b}$ & $<.0001$ \\
\hline$\leq 13$ & $44.1(40.9-47.3)$ & & \\
\hline $14-15$ & $68.5(65.7-71.3)$ & & \\
\hline$\geq 16$ & $72.5(70.1-74.9)$ & & \\
\hline Sex & & $43.4^{c}$ & $<.0001$ \\
\hline Boys & $62.1(59.9-64.4)$ & & \\
\hline Girls & $69.8(67.2-72.4)$ & & \\
\hline Areas & & $3.77^{c}$ & 0.05 \\
\hline Urban & $69.5(66.0-73.1)$ & & \\
\hline Rural & $64.2(61.0-67.4)$ & & \\
\hline Types of school & & $158.5^{c}$ & $<.0001$ \\
\hline Middle school & $59.0(55.8-62.2)$ & & \\
\hline Academic high school & $82.4(79.7-85.1)$ & & \\
\hline Vocational high school & $59.7(56.4-63.0)$ & & \\
\hline
\end{tabular}

positively related to obesity risk. The explanation for the association between short sleep duration and obesity remains unclear, but there are several possible mechanisms explaining the association. First, short sleep duration influences the secretion of a number of hormones, and leads to decreased leptin [35] and increased ghrelin [36] levels, both of which are associated with increased appetite $[37,38]$. In addition, it is hypothesised that tiredness caused by short sleep duration might lead to lower levels of physical activity, in turn promoting weight gain $[39,40]$. This hypothesis was validated by our finding that students with short sleep duration were less physically active than those with non-short sleep duration (15.1\% vs. 19.4\%).

However, contrary to another cross-sectional study showing short sleep duration was associated with obesity only in adolescent boys [41], the positive association in our study was found only among girls, and not among boys. This discrepancy may reflect smaller sample size, less comprehensive adjustment for covariates relating to obesity, ethnic differences, sleep duration category differences, and failure to consider mental health in the analyses in this study. A European study of 3311 adolescents aged 12-17 years indicated that adolescents who slept for shorter duration had higher BMI, body fat and waist circumference, particularly among females [42], consistent with our study. A study of 66,817 adolescents aged 10 to 18 years from China found that the adjusted ORs $(95 \% \mathrm{CI})$ of obesity for students reporting $<5.0 \mathrm{~h}$, $5.0-6.9 \mathrm{~h}$ and $\geq 9.0 \mathrm{~h}$ of sleep were 1.24 (0.97-1.57), 0.94 (0.87-1.01), and $1.42(1.24-1.63)$, respectively, in comparison with their counterparts who slept 7.0-8.9 $\mathrm{h}$ daily, and the study's authors recommended an optimal sleep duration of 7.0-8.0 h daily for prevention of adolescent overweight/obesity [19]. By contrast, our study showed that girls who slept $7 \mathrm{~h}$ per day had a $90 \%$ higher risk of obesity comparing with those who slept 
Table 5 Adjusted odds ratios for obesity according to sleep duration among students in Zhejiang, China

\begin{tabular}{|c|c|c|c|c|c|}
\hline & $<7 \mathrm{~h}$ & $7 \mathrm{~h}$ & $8 \mathrm{~h}$ & $9 \mathrm{~h}$ & $\geq 10 \mathrm{~h}$ \\
\hline \multicolumn{6}{|l|}{ Overall } \\
\hline Total & 2025 & 4262 & 6279 & 3225 & 2612 \\
\hline Obese & 74 & 119 & 184 & 124 & 119 \\
\hline Model 1 & $1.52(1.08-2.12) *$ & $1.30(0.99-1.71)$ & 1.00 & $1.31(0.99-1.73)$ & $1.40(1.05-1.89) *$ \\
\hline Model 2 & $1.55(1.10-2.19) *$ & $1.34(1.02-1.76)^{*}$ & 1.00 & $1.30(0.98-1.71)$ & $1.39(1.03-1.88)$ * \\
\hline Model 3 & $1.60(1.14-2.23)^{\&}$ & $1.36(1.03-1.78) *$ & 1.00 & $1.29(0.97-1.70)$ & $1.39(1.02-1.87)$ * \\
\hline \multicolumn{6}{|l|}{ Female } \\
\hline Total & 1109 & 2394 & 3176 & 1485 & 1095 \\
\hline Obese & 29 & 50 & 58 & 44 & 43 \\
\hline Model 1 & $1.86(1.08-3.22)$ & $1.82(1.14-2.92)$ & 1.00 & $1.40(0.87-2.24)$ & $2.09(1.23-3.58)$ \\
\hline Model 2 & $1.96(1.14-3.35)^{*}$ & $1.89(1.18-3.03)^{\&}$ & 1.00 & $1.38(0.87-2.19)$ & $2.13(1.23-3.69)^{\&}$ \\
\hline Model 3 & $1.97(1.15-3.38) *$ & $1.90(1.18-3.04)^{\&}$ & 1.00 & $1.38(0.86-2.20)$ & $2.12(1.22-3.67)^{\&}$ \\
\hline \multicolumn{6}{|l|}{ Male } \\
\hline Total & 916 & 1868 & 3103 & 1740 & 1517 \\
\hline Obese & 45 & 69 & 126 & 80 & 76 \\
\hline Model 1 & $1.37(0.92-2.03)$ & $1.07(0.77-1.50)$ & 1.00 & $1.27(0.91-1.76)$ & $1.13(0.82-1.56)$ \\
\hline Model 2 & $1.40(0.93-2.10)$ & $1.11(0.80-1.54)$ & 1.00 & $1.25(0.90-1.74)$ & $1.12(0.81-1.54)$ \\
\hline Model 3 & $1.45(0.97-2.16)$ & $1.13(0.81-1.57)$ & 1.00 & $1.25(0.89-1.74)$ & $1.12(0.81-1.54)$ \\
\hline
\end{tabular}

Model 1, adjusted for age group, sex, areas, types of school, paternal and maternal education level. Model 2, additionally adjusted for cigarette use, alcohol use, breakfast consumption, fruit consumption, vegetable consumption, milk consumption, carbonated drinks consumption, physical activity and screen-time. Model 3 , additionally adjusted for loneliness

${ }^{*} P<0.05 ;{ }^{\&} P<0.01$

$8 \mathrm{~h}$ daily, suggesting that sleeping $7.0-7.9 \mathrm{~h}$ daily might also have adverse effect on adolescent health, and that $8.0 \mathrm{~h}$ was the minimum time that middle and high school students need to sleep every day to experience a lower risk of obesity. This finding has very important public health implications, and provides evidence to inform guidance on sleep duration among adolescents.

Meanwhile, our study found that students with a sleep duration $\geq 10$ h per day had $39 \%$ greater odds of obesity compared with those with sleep duration of $8 \mathrm{~h}$ per day. The possible mechanisms underlying the association of prolonged sleep duration with obesity among adolescents remain unclear. One possible explanation is that prolonged sleep duration reflects compensation for poor-quality and/or interrupted sleep, which may be more common among overweight and obese person. A study showed that, compared with normal-weight children, overweight and obese children had less slow-wave sleep (SWS), which plays a major role in body restorative processes and energy metabolism [43].

In the present study, a U-shaped association was found between sleep duration and risk of obesity only among girls, and not among boys. This sex-difference may reflect sex-differences in the physiology of puberty, particularly in body composition. For example, during puberty, boys rapidly increase muscle mass and reduce body fat mass due to increase of testosterone and growth hormone, while girls increase fat mass due to increase of estradiol [44].

Our study had several strengths. First, it included a large and provincially representative sample. Second, a wide range of covariates including socio-demographic status, lifestyle factors (e.g., cigarettes, alcohol, dietary habit, physical activity and screen-time) and mental health (loneliness) were adjusted for in analyses examining the associations of sleep duration and obesity. However, our study also had several limitations. First, the cross-sectional design limits causal inference. Second, all data was self-reported by participants and not objectively measured, which might increase the risk of information bias, including through underestimation of BMI. Third, although analyses were adjusted for most established potential confounding factors, residual confounding might still exist.

\section{Conclusion}

In summary, our study found a U-shaped relationship of sleep duration and obesity among girls, but not among boys, and $8 \mathrm{~h}$ sleep was associated with the lowest risk of obesity among middle and high school students. 


\section{Additional file}

Additional file 1: Table S1. Comparison of characteristics between included and excluded participants. (DOCX $32 \mathrm{~kb}$ )

\section{Abbreviation}

AASM: American academy of sleep medicine; BMl: body mass index; CDCs: centers for disease control and prevention; Cl: confidence interval; DALYs: disability-adjusted life years; GSHS: global school-based student health survey; ORs: odds ratios; SD: standard deviation; WGOC: working group on obesity for children

\section{Acknowledgements}

We thank all of the students and survey staffs for their participation.

\section{Funding}

The work was funded by grant (2016YFC0900502) from National Key Research and Development Program of China.

\section{Availability of data and materials}

The datasets in the current study are available from HW on reasonable request.

\section{Authors' contributions}

HW designed the study, and collected and analyzed the data with MY. JZ and $\mathrm{RH}$ were involved in data interpretation. $\mathrm{HD}$ and FB provided critical comments on the manuscript and revised the manuscript. All the authors have read and approved the final submitted version.

\section{Ethics approval and consent to participate}

This study was approved by the ethics committee of Zhejiang Provincial Centre for Disease Control and Prevention. The institutional review board approved this procedure. Written informed consent was obtained from all students and their guardians.

\section{Consent for publication}

Not applicable.

\section{Competing interests}

The authors declare that they have no competing interests.

\section{Publisher's Note}

Springer Nature remains neutral with regard to jurisdictional claims in published maps and institutional affiliations.

\section{Author details}

'Department of NCDs Control and Prevention, Zhejiang Provincial Center for Diseases Control and Prevention, \#3399 Binsheng road, Binjiang District, Hangzhou, Zhejiang Province, China. ${ }^{2}$ Clinical Trial Service Unit \& Epidemiological Studies Unit (CTSU), Nuffield Department of Population Health, University of Oxford, Oxford, UK. ${ }^{3}$ Medical Research Council Population Health Research Unit, Nuffield Department of Population Health, University of Oxford, Oxford, UK.

Received: 25 April 2018 Accepted: 26 June 2018

Published online: 09 July 2018

\section{References}

1. Collaborators GBDO, Afshin A, Forouzanfar MH, Reitsma MB, Sur P, Estep K, Lee A, Marczak L, Mokdad AH, Moradi-Lakeh M, et al. Health effects of overweight and obesity in 195 countries over 25 years. N Engl J Med. 2017; 377:13-27

2. Friedrich MJ. Global obesity epidemic worsening. JAMA. 2017;318:603.

3. Ma J, Cai CH, Wang HJ, Dong B, Song Y, Hu PJ, Zhang B. The trend analysis of overweight and obesity in Chinese students during 1985 - 2010. Zhonghua Yu Fang Yi Xue Za Zhi. 2012:46:776-80.

4. Fang G, Ronghua Z, Yueqiang F, Haifeng H, Na L. Prevalence of overweight and obesity among children and adolescents in Zhejiang Province. Chin J sch Health. 2013;34:838-40.
5. Bragg F, Tang K, Guo Y, Iona A, Du H, Holmes MV, Bian Z, Kartsonaki C, Chen $Y$, Yang $L$, et al. Associations of general and central adiposity with incident diabetes in Chinese men and women. Diabetes Care. 2018;41:494-502

6. Global Burden of Metabolic Risk Factors for Chronic Diseases C, Lu Y, Hajifathalian K, Ezzati M, Woodward M, Rimm EB, Danaei G. Metabolic mediators of the effects of body-mass index, overweight, and obesity on coronary heart disease and stroke: a pooled analysis of 97 prospective cohorts with 1.8 million participants. Lancet. 2014;383:970-83.

7. Allott EH, Hursting SD. Obesity and cancer: mechanistic insights from transdisciplinary studies. Endocr Relat Cancer. 2015:22:R365-86.

8. Ji M, Tang A, Zhang Y, Zou J, Zhou G, Deng J, Yang L, Li M, Chen J, Qin H, Lin $\mathrm{Q}$. The relationship between obesity, sleep and physical activity in Chinese preschool children. Int J Environ Res Public Health. 2018;15

9. Perng W, Fernandez C, Peterson KE, Zhang Z, Cantoral A, Sanchez BN, Solano-Gonzalez M, Tellez-Rojo MM, Baylin A. Dietary patterns exhibit sexspecific associations with adiposity and metabolic risk in a cross-sectional study in urban Mexican adolescents. J Nutr. 2017;147:1977-85.

10. So HK, Nelson EA, Li AM, Guldan GS, Yin J, Ng PC, Sung RY. Breakfast frequency inversely associated with BMI and body fatness in Hong Kong Chinese children aged 9-18 years. Br J Nutr. 2011;106:742-51.

11. Calamaro CJ, Park S, Mason TB, Marcus CL, Weaver TE, Pack A, Ratcliffe SJ. Shortened sleep duration does not predict obesity in adolescents. J Sleep Res. 2010;19:559-66.

12. Sivertsen B, Pallesen S, Sand L, Hysing M. Sleep and body mass index in adolescence: results from a large population-based study of Norwegian adolescents aged 16 to 19 years. BMC Pediatr. 2014;14:204.

13. Liu X, Liu L, Owens JA, Kaplan DL. Sleep patterns and sleep problems among schoolchildren in the United States and China. Pediatrics. 2005;115: 241-9.

14. Wang Y. Cross-national comparison of childhood obesity: the epidemic and the relationship between obesity and socioeconomic status. Int J Epidemiol. 2001;30:1129-36.

15. Beebe DW, Lewin D, Zeller M, McCabe M, MacLeod K, Daniels SR, Amin R. Sleep in overweight adolescents: shorter sleep, poorer sleep quality, sleepiness, and sleep-disordered breathing. J Pediatr Psychol. 2007:32:69-79.

16. Hassan F, Davis MM, Chervin RD. No independent association between insufficient sleep and childhood obesity in the National Survey of Children's health. J Clin Sleep Med. 2011;7:153-7.

17. Danielsen YS, Pallesen S, Stormark KM, Nordhus IH, Bjorvatn B. The relationship between school day sleep duration and body mass index in Norwegian children (aged 10-12). Int J Pediatr Obes. 2010;5:214-20.

18. Lytle LA, Pasch KE, Farbakhsh K. The relationship between sleep and weight in a sample of adolescents. Obesity (Silver Spring). 2011;19:324-31.

19. Wu J, Wu H, Wang J, Guo L, Deng X, Lu C. Associations between sleep duration and overweight/obesity: results from 66,817 Chinese adolescents. Sci Rep. 2015:5:16686.

20. Wang H, Hu R, Zhong J, Du H, Fiona B, Wang M, Yu M. Binge drinking and associated factors among school students: a cross-sectional study in Zhejiang Province, China. BMJ Open. 2018;8:e021077.

21. Centers for Disease Control and Prevention. 2017 State and Local Youth Risk Behavior Survey; [https://www.cdc.gov/healthyyouth/data/yrbs/ questionnaires.htm]

22. World Health Organization.Global school-based students health survey(GSHS) [http://www.who.int/ncds/surveillance/gshs/nepal/en/].

23. Group of China Obesity Task F. Body mass index reference norm for screening overweight and obesity in Chinese children and adolescents. Zhonghua Liu Xing Bing Xue Za Zhi. 2004;25:97-102.

24. Paruthi S, Brooks LJ, D'Ambrosio C, Hall WA, Kotagal S, Lloyd RM, Malow BA Maski K, Nichols C, Quan SF, et al. Consensus statement of the American Academy of sleep medicine on the recommended amount of sleep for healthy children: methodology and discussion. J Clin Sleep Med. 2016;12: 1549-61.

25. Pengid S, Peltzer K. Alcohol use and associated factors among adolescent students in Thailand. West Indian Med J. 2012;61:890-6.

26. Himes $\mathrm{JH}_{\mathrm{H}}$ Hannan $\mathrm{P}$, Wall M, Neumark-Sztainer D. Factors associated with errors in self-reports of stature, weight, and body mass index in Minnesota adolescents. Ann Epidemiol. 2005;15:272-8.

27. Morrissey SL, Whetstone LM, Cummings DM, Owen LJ. Comparison of selfreported and measured height and weight in eighth-grade students. J Sch Health. 2006;76:512-5 
28. Fonseca H, Silva AM, Matos MG, Esteves I, Costa P, Guerra A, Gomes-Pedro J. Validity of BMI based on self-reported weight and height in adolescents. Acta Paediatr. 2010;99:83-8.

29. Perez A, Gabriel K, Nehme EK, Mandell DJ, Hoelscher DM. Measuring the bias, precision, accuracy, and validity of self-reported height and weight in assessing overweight and obesity status among adolescents using a surveillance system. Int J Behav Nutr Phys Act. 2015;12(Suppl 1):S2.

30. Brettschneider AK, Rosario AS, Ellert U. Validity and predictors of BMI derived from self-reported height and weight among 11- to 17-year-old German adolescents from the KiGGS study. BMC Res Notes. 2011;4:414.

31. Bowring AL, Peeters A, Freak-Poli R, Lim MS, Gouillou M, Hellard M. Measuring the accuracy of self-reported height and weight in a community-based sample of young people. BMC Med Res Methodol. 2012;12:175.

32. Jean-Louis G, Williams NJ, Sarpong D, Pandey A, Youngstedt S, Zizi F, Ogedegbe G. Associations between inadequate sleep and obesity in the US adult population: analysis of the national health interview survey (19772009). BMC Public Health. 2014;14:290.

33. Wheaton AG, Jones SE, Cooper AC, Croft JB. Short sleep duration among middle school and high school students - United States, 2015. MMWR Morb Mortal Wkly Rep. 2018;67:85-90.

34. Miller MA, Kruisbrink M, Wallace J, Ji C, Cappuccio FP. Sleep duration and incidence of obesity in infants, children and adolescents: a systematic review and meta-analysis of prospective studies. Sleep. 2018;

35. Spiegel K, Leproult R, L'Hermite-Baleriaux M, Copinschi G, Penev PD, Van Cauter E. Leptin levels are dependent on sleep duration: relationships with sympathovagal balance, carbohydrate regulation, cortisol, and thyrotropin. J Clin Endocrinol Metab. 2004;89:5762-71.

36. Taheri S, Lin L, Austin D, Young T, Mignot E. Short sleep duration is associated with reduced leptin, elevated ghrelin, and increased body mass index. PLoS Med. 2004;1:e62.

37. Levin F, Edholm T, Schmidt PT, Gryback P, Jacobsson H, Degerblad M, Hoybye C, Holst JJ, Rehfeld JF, Hellstrom PM, Naslund E. Ghrelin stimulates gastric emptying and hunger in normal-weight humans. J Clin Endocrinol Metab. 2006;91:3296-302.

38. Mars M, de Graaf C, de Groot CP, van Rossum CT, Kok FJ. Fasting leptin and appetite responses induced by a 4-day 65\%-energy-restricted diet. Int J Obes. 2006:30:122-8.

39. Schmid SM, Hallschmid M, Jauch-Chara K, Wilms B, Benedict C, Lehnert H, Born J, Schultes B. Short-term sleep loss decreases physical activity under free-living conditions but does not increase food intake under timedeprived laboratory conditions in healthy men. Am J Clin Nutr. 2009;90: 1476-82.

40. Taheri S. The link between short sleep duration and obesity: we should recommend more sleep to prevent obesity. Arch Dis Child. 2006;91:881-4.

41. Suglia SF, Kara S, Robinson WR. Sleep duration and obesity among adolescents transitioning to adulthood: do results differ by sex? J Pediatr. 2014;165:750-4

42. Garaulet M, Ortega FB, Ruiz JR, Rey-Lopez JP, Beghin L, Manios Y, CuencaGarcia M, Plada M, Diethelm K, Kafatos A, et al. Short sleep duration is associated with increased obesity markers in European adolescents: effect of physical activity and dietary habits. The HELENA study. Int J Obes. 2011; 35:1308-17.

43. Pacheco SR, Miranda AM, Coelho R, Monteiro AC, Braganca G, Loureiro HC Overweight in youth and sleep quality: is there a link? Arch Endocrinol Metab. 2017:61:367-73.

44. Roche A, Sun S. Human growth: assessment and interpretation. Cambridge: Cambridge University Press; 2003.

\section{Ready to submit your research? Choose BMC and benefit from:}

- fast, convenient online submission

- thorough peer review by experienced researchers in your field

- rapid publication on acceptance

- support for research data, including large and complex data types

- gold Open Access which fosters wider collaboration and increased citations

- maximum visibility for your research: over $100 \mathrm{M}$ website views per year

At BMC, research is always in progress.

Learn more biomedcentral.com/submissions 